\title{
COMPARATIVE STUDY BETWEEN THE TRADITIONAL TEACHING METHOD AND THE ONLINE TEACHING METHOD
}

\author{
Gabriela Leuțanu \\ "Ion Creangă" State Pedagogical University, Chisinau, PhD student \\ Psychologist-Psychotherapist at the Individual Psychology Office \\ E-mail: leutanug@yahoo.com \\ ORCID ID: 0000-0001-8909-1161
}

\begin{abstract}
In a society in which devices tend to occupy more and more place in the lives of young people and not only, but educators are the subject of this study, a harmonious intertwining of modern methods and the use of multiple applications, which arouse the student's interest and methods. Traditional, would be the best way to educate young people.
\end{abstract}

Objectives: The aim of the research was to demonstrate with accurate data, based on a thorough research, that students do not agree with the method exclusively online, but prefer face-to-face education, but with the use of modern methods, applications and educational platforms. Through this study, those interested will be informed of the importance of the harmonious combination of the two types of teaching methods, traditional and modern, online, which are in a relationship of complementarity.

Materials and methods: The research method used is represented by the comparative study on different specialized works in this field and the survey, which was conducted on a group of 60 high school students, on the effectiveness of traditional teaching methods, compared to online teaching. The purpose of the survey in this study was to draw some conclusions about the effectiveness of the methods approached, in the context of the pandemic situation in the last calendar year, which put Romanian education in front of an unprecedented situation, that of online school exclusively or that of the scenario. hybrid, half of the students being in classes, physically, the other half, attending classes simultaneously, but from home, through the platform used, Classroom.

Results: Modern methods that include digital learning would seem, at first glance, quite attractive to students, they prove their effectiveness, given that they are not exclusive. The contents become easier to remember and assimilate, compared to the voluminous textbooks, digitization, the use of modern teaching methods becoming a necessity of our times, through the broad perspective it offers. The main drawback is that the Internet provides information, often false or invalid, for this reason, the intervention of the teacher to make informed references, to guide sources and guide the process of verifying the information, being absolutely necessary. Digital educational tools and technologies, such as social platforms, help teachers to create and manage workgroups, a major advantage of this method of work being the saving of time and increasing learning productivity.

Conclusions: I consider that the traditional methods should not be replaced, but perfected and combined, in the didactic act, with the modern ones, they being in a relationship of complementarity. Teaching becomes more efficient if we harmoniously combine traditional methods with digital tools and technology. For all its advantages, digital education would not survive without the traditional one, as devices cannot replace the guidance, advice, empathy of a teacher, and the smell of an old book on the shelf, which triggers involuntary memory, can not be replaced. for the book carries between its pages thousands of glances, of the hundreds of generations that have passed through it.

Keywords: learning, school, traditional teaching, online teaching. 


\section{OBJECTIVES}

If we were to imagine the evolution of society as a tree with multiple branches, education would be the root, which is the basis for the development of all areas of activity. This aspect is strong enough to consider that education is a condition of evolution. The dyad of traditional education-modern education has been a particularly controversial topic in recent decades, in the context of social, political, economic and moral changes that humanity is going through. In the last year, due to the pandemic conditions, the hiatus between the two camps has intensified.

The literature has highlighted the limits of the educational styles circumscribed to the school face to face, based on mostly classical methods and the online school, based on modern methods, in which technology prevails. Thus, if in the case of traditional methods the emphasis is on mechanical memorization of theoretical elements, modern methods are based on logic and the training of emotional intelligence. The traditional school is based on learning through the accumulation of information and skills, unlike the modern one, which is based on activities undertaken through audio and visual means, making the teaching-learning process a pleasant one. Traditional methods are based on the development of basic skills, unlike modern ones, which offer the opportunity to access a vast, playful and formative content, from anywhere and anytime, with the help of devices. The latter develop critical thinking: "To think critically means to have valuable and useful knowledge, to have rational beliefs, to propose personal opinions, to accept that one's own ideas can be discussed and evaluated, to build sufficient arguments for one's own opinions, to participate actively and collaborate in finding solutions. "[3, p. 298].

In a society in which devices tend to occupy more and more place in the lives of young people and not only, but educators are the subject of this study, a harmonious intertwining of modern methods and the use of multiple applications, which arouse the student's interest and methods. Traditional, would be the best way to educate young people.

From this point of view, the present study aims to demonstrate with accurate data, based on a thorough research, the fact that students do not agree with the method exclusively online, but prefer face-to-face education, but using modern methods, applications and platforms proven effective in the online environment.

The hypothesis we start from is that the school can change, so as to teach students that adaptability is the most important component they need to develop, as society is constantly changing. The new challenges and problems that students face, adapting to new technologies, actually prepare them for life.

Through this study, those interested will be informed about the importance of the harmonious combination of the two types of teaching methods, traditional and modern, online, they being in a relationship of complementarity.

\section{MATERIALS AND METHODS}

The methods specific to the traditional school, expository or frontal, leave the impression that it would no longer be in accordance with the new principles of active and conscious participation of the student, in the context of a modern society, which shifts the emphasis on critical thinking. Teaching methods, regardless of their type, can be defined as "ways of action with which students, independently or under the guidance of the teacher, acquire knowledge, form skills and abilities, aptitudes, attitudes, worldview and life. ."[2, p. 126].

Due to the psycho-individual peculiarities of the students, a varied use of these methods is required in the didactic practice, their significance depending, to a large extent, on the context in which they are used, but especially on the user and his ability to adapt them to the requirements. individual and group. Students are not just recipients of information, but active participants in education, and in school it is important to encourage, through the diversity of methods used, participatory behavior that means "the step from learning, to learning to be and become, to say the readiness to deal with situations, acquiring the desire for commitment and action. "[1, p/143].

As a research method in this paper, we used the comparative study on different specialized papers in this field and the survey, which was conducted on a group of 60 students from the High School on the efficiency of traditional teaching methods, compared to online teaching.

The purpose of the survey in this study was to draw some conclusions about the effectiveness of the methods approached, in the context of the pandemic situation in the last calendar year, which put Romanian education in front of an unprecedented situation, that of online school exclusively or that of the scenario. hybrid, half of the students being in classes, physically, the other half, attending classes simultaneously, but from home, through the platform used, Classroom. 
Students who went through all three scenarios during this period, (green which requires physical presence at school of the full student body, yellow, which requires half of the student body to be physically present, by rotation, the other half being online and the red script, in which all the courses took place on the school platform, on Meet.) had informed answers to all these questions. As a result of going through all these scenarios, the students were interviewed, the purpose being to receive a particularly useful feedback in the adoption of improving measures regarding the instructive-educational process at the level of the school unit. We present below the questions of the questionnaire, with the mention that it was addressed to the three groups of students that we constituted from the enrollment of two classes: one of the ninth (20 students), at the beginning of the high school cycle, the other, of the XII -a (20 students), at the end of high school. The third group (20 students) consisted of 10 th grade students, halfway to graduation.

\section{RESULTS}

$70 \%$ of respondents preferred physical attendance at classes, $20 \%$ hybrid attendance and $10 \%$ online attendance.

Among the advantages of traditional education, students responded differently, cumulatively, their answers focused on: $60 \%$ socialization, $30 \%$ competitive spirit and $10 \%$ emotional closeness to colleagues and teachers.

Among the disadvantages of traditional education and implicitly of its specific methods, $75 \%$ complained about unattractive information and not adapted to the needs of knowledge, $15 \%$ the large volume of information in each subject, and $10 \%$ the mechanical learning that expository methods require.

Online education was evaluated as follows: among the advantages, $65 \%$ scored the use of new, motivating, attractive applications, $25 \%$ the lightness of the program and $10 \%$ the evaluation methods. Among the disadvantages, $55 \%$ pointed out the problems related to internet speed or connection, $25 \%$ lack of socialization and $20 \%$ lack of emotional and motivational connection.

For the most part, students use the smartphone, $55 \%$ of them, to connect to Classroom-Meet, $15 \%$ tablet, $15 \%$ laptop and $15 \%$ PC.

The hours spent in front of the devices are many: $80 \%$ spend between 7 and 9 hours, $15 \%$, between $4-7$ hours and only $5 \%$ under 4 hours.

$70 \%$ answered that most of these online courses help them, in the absence of physical presence at school, $25 \%$ answered that it does not help them, and $5 \%$ answered in the affirmative.

Between the two frequencies at courses, physical or online, $80 \%$ of respondents preferred physical presence, only $20 \%$ online.

$90 \%$ thought that they are modern and traditional methods are complementary, $7 \%$ answered "Mostly" and $3 \%$ answered "No".

\section{CONCLUSIONS}

As the analysis of the results of the above questionnaire shows, the students answered as honestly as possible, referring to their personal experience in the last year of school. What is interesting is the analysis of the answers on the three groups of students. The first group, of 20 ninth grade respondents, preferred the online attendance at classes, in proportion of $70 \%$, while the group of 12 th grade students preferred the class attendance (88\% of respondents), seeing better its usefulness for acquiring the knowledge necessary to pass the baccalaureate exam. In the same note, students in the mixed group, of 15 students of the ninth and 15th of the twelfth, kept their preferences specific to the age group and interests: $70 \%$ of those in the ninth considered that online presence benefits them more, and $90 \%$ of 12 th graders advocated for physical attendance at school.

In other words, the students of the mixed group, regardless of whether they are ninth or twelfth grade, preferred, in proportion of $79 \%$, the combination of traditional methods with modern ones, in any scenario.

Given the aspects mentioned above, digital learning, modern methods that include it, would seem, at first glance, quite attractive to students, they prove their effectiveness, given that they are not exclusive. The contents become easier to remember and assimilate, compared to the voluminous textbooks, digitization, the use of modern teaching methods becoming a necessity of our times, through the broad perspective it offers. The main drawback is that the Internet provides information, often false or invalid, for this reason, the intervention of the teacher to make informed references, to guide sources and guide the process of verifying 
the information, being absolutely necessary. Digital educational tools and technologies, such as social platforms, help teachers to create and manage work groups, a major advantage of this method of work being the saving of time and increasing learning productivity.

Given the mentioned aspects, I conclude that the traditional methods should not be replaced, but perfected and combined, in the didactic act, with the modern ones, being in a relationship of complementarity. Teaching becomes more efficient if we harmoniously combine traditional methods with digital tools and technology. For all its advantages, digital education would not survive without the traditional one, as devices cannot replace the guidance, advice, empathy of a teacher, and the smell of an old book on the shelf, which triggers involuntary memory, cannot be replaced, for the book carries between its pages thousands of glances, of the hundreds of generations that have passed through it.

\section{REFERENCE LIST}

1. Dumitru, I, Development of critical thinking and effective learning, West Publishing House, Timișoara, 2000.ISBN 973-36+0332-5

2. Ionescu, M, Radu, I, Modern Didactics, Dacia Publishing House, Cluj-Napoca, 2001. ISBN 973-35-1084$\mathrm{X}$

3. Marcu, V. Filimon, Psychopedagogy for teacher training, Publishing House University of Oradea, 2003. ISBN 973-61-3266-8, 978-973-61-3266-7

4. Mihai Aniței, Experimental Psychology, Polirom Publishing House, Iași, 2016. ISBN 978-973-46-0541-5 